\title{
Lung Volume Changes During Cleaning of Closed Endotracheal Suction Catheters: A Randomized Crossover Study Using Electrical Impedance Tomography
}

\author{
Amanda Corley RN, Nicola Sharpe RN, Lawrence R Caruana, \\ Amy J Spooner RN, and John F Fraser MB ChB PhD
}

\begin{abstract}
BACKGROUND: Airway suctioning in mechanically ventilated patients is required to maintain airway patency. Closed suction catheters (CSCs) minimize lung volume loss during suctioning but require cleaning post-suction. Despite their widespread use, there is no published evidence examining lung volumes during CSC cleaning. The study objectives were to quantify lung volume changes during CSC cleaning and to determine whether these changes were preventable using a CSC with a valve in situ between the airway and catheter cleaning chamber. METHODS: This prospective randomized crossover study was conducted in a metropolitan tertiary ICU. Ten patients mechanically ventilated via volume-controlled synchronized intermittent mandatory ventilation (SIMV-VC) and requiring manual hyperinflation (MHI) were included in this study. CSC cleaning was performed using 2 different brands of CSC (one with a valve [Ballard Trach Care 72, Kimberly-Clark, Roswell, Georgia] and one without [Portex Steri-Cath DL, Smiths Medical, Dublin, Ohio]). The maneuvers were performed during both SIMV-VC and MHI. Lung volume change was measured via impedance change using electrical impedance tomography. A mixed model was used to compare the estimated means. RESULTS: During cleaning of the valveless CSC, significant decreases in lung impedance occurred during MHI ( -2563 impedance units, 95\% CI 2213-2913, $P<.001$ ), and significant increases in lung impedance occurred during SIMV (762 impedance units, 95\% CI 452-1072, $P<.001$ ). In contrast, cleaning of the CSC with a valve in situ resulted in non-significant lung volume changes and maintenance of normal ventilation during MHI and SIMV-VC, respectively (188 impedance units, $95 \%$ CI -136 to $511, P=.22$; and 22 impedance units, $95 \%$ CI -342 to $299, P=.89$ ). CONCLUSIONS: When there is no valve between the airway and suction catheter, cleaning of the CSC results in significant derangements in lung volume. Therefore, the presence of such a valve should be considered essential in preserving lung volumes and uninterrupted ventilation in mechanically ventilated patients. Key words: suctioning; lung volume; lung volume measurement; alveolar de-recruitment; electrical impedance tomography; mechanical ventilation. [Respir Care 2014;59(4):497-503. () 2014 Daedalus Enterprises]
\end{abstract}

\section{Introduction}

The goal of protective ventilation strategies is to minimize the shear forces associated with repeated de-recruit-

\footnotetext{
All authors are affiliated with the Critical Care Research Group, The Prince Charles Hospital, University of Queensland, Brisbane, Queensland, Australia.
}

The authors have disclosed a relationship with Kimberly-Clark, which provided 10 Ballard Trach Care 72 closed suction catheters and an unrestricted grant for partial funding of this study. This research was sup- ment and re-expansion of alveoli in an attempt to prevent the development of ventilator-induced lung injury. ${ }^{1}$ Endotracheal suctioning leads to significant lung de-recruit-

\footnotetext{
ported by a Health Research Fellowship from the Office of Health and Medical Research, Queensland Health.
}

Correspondence: Amanda Corley RN, Critical Care Research Group, The Prince Charles Hospital, University of Queensland, Brisbane, Queensland 4072, Australia. E-mail: amanda_corley@health.qld.gov.au.

DOI: $10.4187 /$ respcare. 02601 


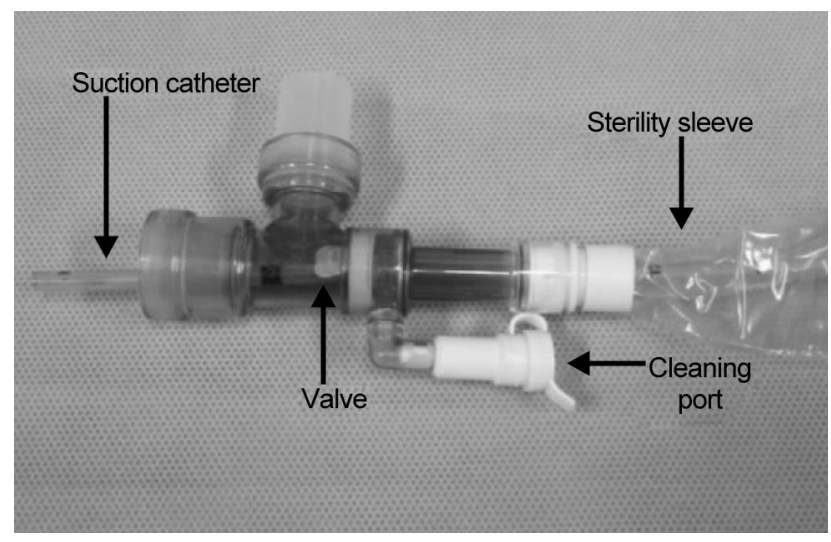

Fig. 1. The Ballard Trach Care 72 closed suction catheter.

ment ${ }^{2-4}$; however, it is essential in maintaining a patent airway in mechanically ventilated patients. It has been demonstrated that closed suctioning minimizes loss of lung volume compared with open suctioning, largely because disconnection from the ventilator circuit is not required..$^{2,4,5}$ This has led to its increased use particularly in patients requiring long-term ventilation.

Closed suction catheters (CSCs) sit within a sterile sleeve, in line with the ventilator circuit and the patient's airway. During airway suctioning, the catheter is manually advanced into the airway, and suction is applied while the catheter is being withdrawn. After each suction, the CSC requires flushing with normal saline while suction is simultaneously applied. This cleaning process is necessary to prevent the buildup of secretions within the catheter, but a prolonged period of suction may be needed to adequately clean thick tenacious secretions from the lumen of the catheter. During the cleaning of a CSC in a mechanically ventilated patient in our ICU, the investigators made an incidental finding while measuring the effects of suctioning on lung volume loss. It was observed that, after airway suctioning was complete and during cleaning of the CSC, there was a marked loss of lung volume.

We hypothesized that the observed loss of lung volume during CSC cleaning was due to the absence of a valve between the CSC and the patient's airway in the product that was used for closed airway suctioning at the time (Portex Steri-Cath DL, Smiths Medical, Dublin, Ohio). The Ballard Trach Care 72 closed suction catheter (Kimberly-Clark Health Care, Roswell, Georgia) has a separate cleaning chamber that is isolated from the patient's airway and ventilator circuit by a valve that closes once the catheter has been withdrawn into the sterility sleeve (Fig. 1). One unpublished bench study examined ventilator volume loss during CSC cleaning by attaching a ventilator to a test lung. ${ }^{6}$ This study demonstrated that almost all volume was removed from the test lung during cleaning of the CSC without a valve. In contrast, when there was a valve in

\section{QUICK LOOK}

\section{Current knowledge}

Closed-circuit suction catheters prevent loss of lung volume during airway suctioning and minimize hypoxemic events. The impact of cleansing the catheter following suctioning is not well described.

\section{What this paper contributes to our knowledge}

When closed-circuit suctioning is used, a valve in place between the patient's airway and the catheter cleaning chamber prevents lung de-recruitment and ventilation interruption during cleaning of the catheter.

place between the ventilator circuit and the CSC, very little volume was lost during CSC cleaning. We were interested in exploring these findings further in the clinical in vivo situation, removed from the standardized conditions of a bench experiment.

Loss of lung volume can be safely and accurately measured at the bedside using electrical impedance tomography. ${ }^{6-8}$ A relatively new tool, electrical impedance tomography measures change in resistance or biological impedance to current flow. ${ }^{9,10}$ Sixteen electrodes placed circumferentially around the thorax record the changes in impedance caused by the changes in air volume within the thorax during inspiration and expiration. ${ }^{10,11}$ The recorded changes can be used to create images of ventilation within the lungs both globally and regionally. ${ }^{10,12,13}$ Due to the strong linear relationship between impedance change and volume change, ${ }^{14,15}$ changes in lung volume can be accurately measured. In particular, this measurement technique has been shown to reliably and accurately detect changes in lung volume during and after endotracheal suctioning. ${ }^{2,6,7}$

In this study, we aimed to compare the loss of endexpiratory lung volume (EELV) during CSC cleaning when using a CSC with a valve and without a valve to determine whether the valve's presence preserved lung volume during manual hyperinflation (MHI) and volume-controlled synchronized intermittent mandatory ventilation (SIMV-VC).

\section{Methods}

Before study commencement, ethical approval was obtained from our institution's Human Ethics and Research Committee (EC27105). Written informed consent was obtained from participants before their scheduled cardiac surgery, and the study was conducted in accordance with the ethical standards laid down in the 1964 Declaration of Helsinki.

Each consenting patient was then screened on return to the ICU. Patients were deemed eligible if they met all of 
Table 1. Mean Differences in End-Expiratory Lung Impedance (EELI) via Ventilation Mode (Manual Hyperinflation [MHI] and VolumeControlled Synchronized Intermittent Mandatory Ventilation [SIMV-VC]) and Catheter Type

\begin{tabular}{lcccc}
\hline \hline $\begin{array}{c}\text { Ventilation Mode/ } \\
\text { Catheter Type }\end{array}$ & $\begin{array}{c}\text { Mean EELI at Baseline } \\
\text { (Impedance Units) }\end{array}$ & $\begin{array}{c}\text { Mean EELI During Cleaning } \\
\text { (Impedance Units) }\end{array}$ & $\begin{array}{c}\text { Difference } \\
\text { (Impedance Units) }\end{array}$ & $95 \%$ CI \\
\hline MHI with valve & 979 & 1166 & 188 & -136 to 511 \\
MHI without valve & 930 & -1633 & -2563 & 2213 to 2913 \\
SIMV-VC with valve & 286 & 308 & +22 & -342 to 299 \\
SIMV-VC without valve & 292 & 1054 & 762 & 452 to 1072 \\
\hline
\end{tabular}

the following inclusion criteria: $\geq 18$ y of age, post-cardiac surgery, ventilated in SIMV-VC mode, and required MHI as part of their standard treatment. Patients were excluded if they required ongoing cardiac pacing, had an open sternum, had PEEP $\geq 10 \mathrm{~cm} \mathrm{H}_{2} \mathrm{O}$, were unlikely to be able to tolerate MHI due to desaturation or hemodynamic instability (defined as arterial oxygen saturation $\left(\mathrm{S}_{\mathrm{aO}_{2}}\right) \leq 90 \%$, mean arterial pressure $<55 \mathrm{~mm} \mathrm{Hg}$, $\mathrm{P}_{\mathrm{aO}_{2}}<70 \mathrm{~mm} \mathrm{Hg}$, and/or active bleeding with drain loss of $>100 \mathrm{~mL}$ in last hour), or required any change in ventilator settings between cleaning maneuvers.

\section{Protocol for Cleaning of Closed Suction Catheter}

All cleaning procedures were performed by 2 critical care nurses (NS and AC). Patients were positioned in a supine position. CSC cleaning was tested during 2 modes of ventilation (MHI and SIMV-VC) and using 2 types of CSC (Portex Steri-Cath DL and Ballard Trach Care 72). The order of catheter testing and mode of ventilation were randomized using a sequentially numbered opaque envelope system so that, for each patient, 4 catheter-cleaning episodes were performed, each for a duration of $5 \mathrm{~s}$.

While assessing the effects of CSC cleaning during SIMV-VC, ventilator settings (Puritan Bennett 840 ventilator, Covidien, Mansfield, Massachusetts) were standardized to: SIMV-VC mode with a tidal volume of $6-8 \mathrm{~mL} /$ $\mathrm{kg}$, inspiratory flow trigger of $1.5 \mathrm{~L} / \mathrm{min}$, peak flow of $50 \mathrm{~L} / \mathrm{min}, \mathrm{PEEP}=5 \mathrm{~cm} \mathrm{H} \mathrm{H}_{2}$, and $\mathrm{F}_{\mathrm{IO}_{2}}$ set by the intensive care specialist to maintain $\mathrm{S}_{\mathrm{pO}_{2}} \geq 95 \%$.

While performing CSC cleaning during MHI, breaths were delivered at 15 breaths/min using a Mapleson C modified circuit (Mayo Healthcare, Rosebery, Australia), and a manometer was placed in line with the circuit to maintain PEEP at between 4 and $6 \mathrm{~cm} \mathrm{H}_{2} \mathrm{O}$ and a peak inspiratory pressure of $25-30 \mathrm{~cm} \mathrm{H}_{2} \mathrm{O}$.

Each CSC cleaning was performed in the following manner. (1) The suction catheter was fully retracted and contained within the sterility sleeve (ie, outside the patient's endotracheal tube). (2) Suction (standardized to $-150 \mathrm{~mm} \mathrm{Hg}$ ) was applied for $5 \mathrm{~s}$ by depressing the suction button on the closed suction device, and $10 \mathrm{~mL}$ of normal saline was instilled simultaneously to clean the suction catheter. (3) Twenty min were allowed to elapse between each CSC cleaning to negate any washout effect. (4) The suction catheter was not introduced into the patient's airway during the study.

\section{Lung Volume Measurement}

EELV change was assessed (EIT Evaluation Kit 2, Dräger, Lübeck, Germany). After self-test of the device following the manufacturer's instructions, end-expiratory lung impedance (EELI) was measured at baseline (immediately before each of the cleaning maneuvers) and during each of the cleaning episodes performed. The linear relationship between impedance change and volume change has been established previously ${ }^{14,15}$ such that the change in EELI is seen as an accurate reflection of change in EELV.

\section{Statistical Analysis}

To account for the repeated results from the same subject, a mixed model was used to analyze the data. The model included a random intercept for each subject with a factor of ventilation type (MHI or SIMV-VC) or catheter type (valve or no valve). A pairwise comparison of the estimated marginal means was performed to ascertain the change in EELI during CSC cleaning compared with the baseline. Data were normally distributed. Ten subjects were required for a power of $80 \%$ at $5 \%$ significance.

\section{Results}

Nineteen patients consented to the study. Two patients did not meet inclusion criteria after their surgery due to hemodynamic instability, and 7 patients had their surgery cancelled. Therefore, 10 patients were randomized and studied, 8 of whom were male, with a mean age of $55.8 \pm 10.5$ y. Five patients underwent coronary artery bypass graft surgery, 4 underwent valve replacement, and one patient had a myomectomy. The study findings are summarized in Table 1.

\section{Manual Hyperinflation}

When ventilating with MHI, cleaning of the CSC with a valve in situ was not associated with a significant dif- 

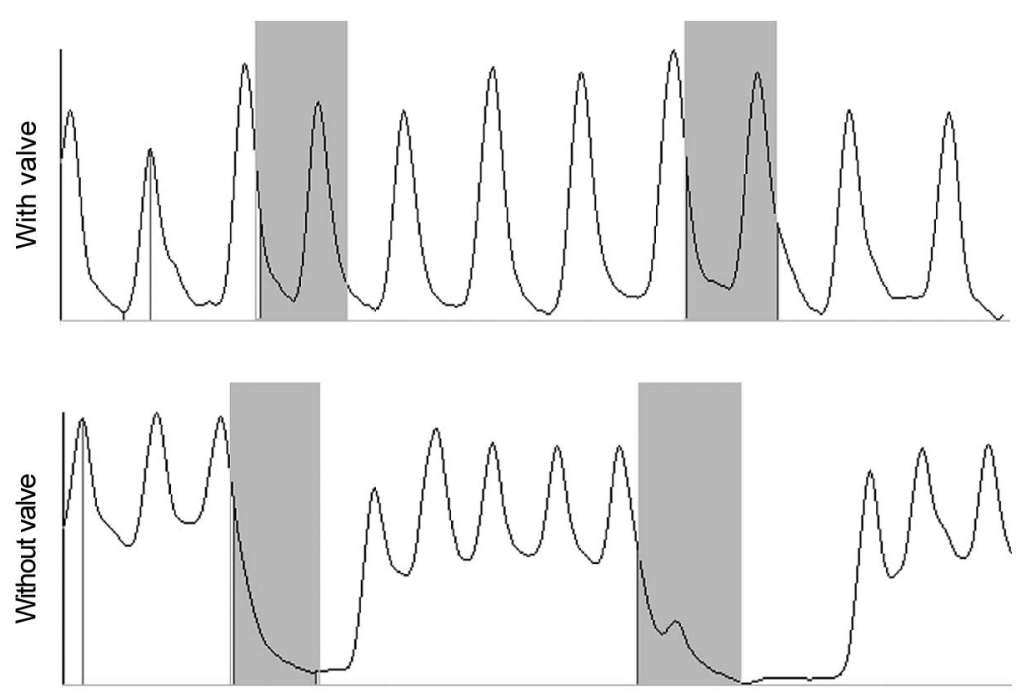

Fig. 2. Electrical impedance tomography ventilation waveforms during manual hyperinflation. The shaded areas denote the cathetercleaning periods.
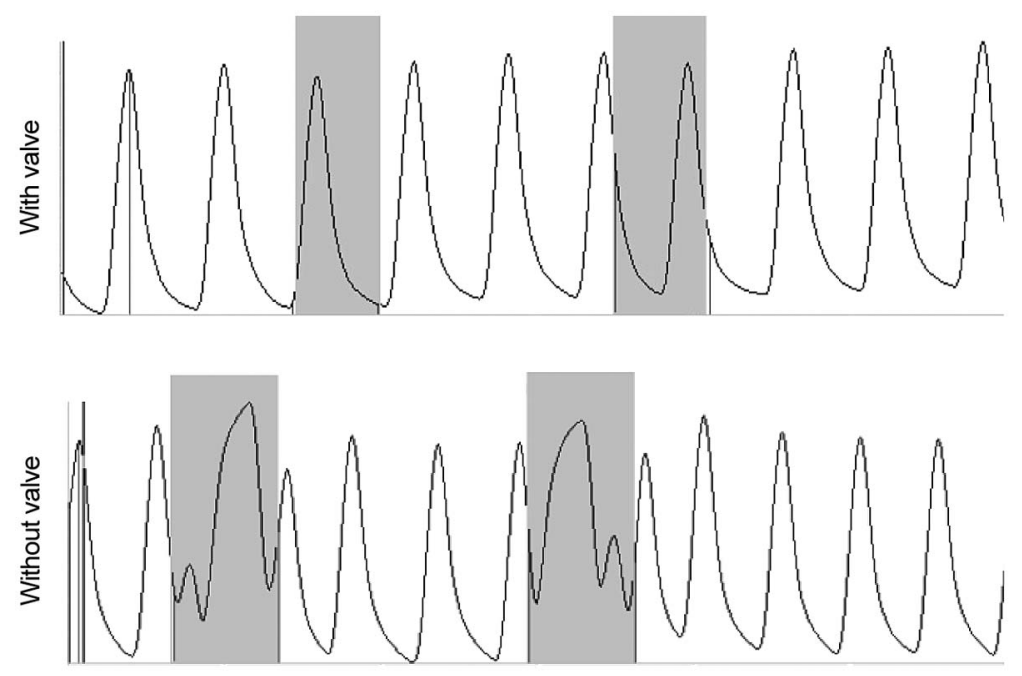

Fig. 3. Electrical impedance tomography ventilation waveforms during volume-controlled synchronised intermittent mandatory ventilation. The shaded areas denote the catheter-cleaning periods.

ference in mean EELI from baseline (188 impedance units, $95 \% \mathrm{CI}-136$ to $511, P=.22)$. However, when cleaning the CSC was performed with no valve between the airway and the sterility sleeve in the same mode of ventilation, there was a statistically significantly decrease in mean EELI from baseline ( -2563 impedance units, 95\% CI 2213-2913, $P<.001)$, indicating a significant loss of EELV during cleaning. Figure 2 provides an example of these findings.

\section{Synchronized Intermittent Mandatory Ventilation}

During SIMV-VC, there were no significant changes in EELI during CSC cleaning when using a CSC with a valve
(+22 impedance units, $95 \% \mathrm{CI}-342$ to $299, P=.89)$. In contrast, there were large increases in EELI observed during CSC cleaning when using a CSC without a valve $(+762$ impedance units, 95\% CI 452-1072, $P<.001)$, indicating significant increases in EELV and interruption to delivered ventilation. Figure 3 provides an example of these findings.

\section{Discussion}

The results of this study demonstrate that, when ventilating via MHI and SIMV-VC, the presence of a valve between the patient's airway and the CSC protects lung volumes and maintains uninterrupted ventilation during 
cleaning of the CSC. CSC cleaning without such a valve results in significant lung de-recruitment during $\mathrm{MHI}$ and significant increases in lung volume and derangements to normal ventilation during SIMV-VC. Although not supported by any evidence, there is a presumption by clinicians that the application of suction during CSC cleaning has minimal or negligible effect on lung volume and ventilation. This study clearly establishes that this is not the case and that EELV is significantly affected by cleaning of a CSC without a valve.

Cleaning of the CSC is essential after airway suctioning because, without adequate cleaning of the CSC after suctioning, colonized bacteria from the catheter may spread to the ventilator circuit and lower respiratory tract, increasing the chance of ventilator-associated pneumonia. ${ }^{16-19} \mathrm{Al}-$ though it is critical that cleaning of the CSC is performed after suctioning, it is evident from these data that there must be a valve present between the patient's airway and the cleaning chamber to prevent interruption to ventilation and loss of lung volume during this procedure. For the purposes of this study, catheter-cleaning time was standardized to $5 \mathrm{~s}$. In clinical practice, this period may be much longer depending on how thick and tenacious the patient's secretions are and how difficult they are to remove from the catheter. Therefore, the actual period of de-recruitment and ventilation interruption may be far longer, resulting in greater loss of lung volume and longer interruptions to ventilation.

Significant lung de-recruitment was observed during MHI when using the CSC without a valve. It is interesting to note that extensive research has been conducted to examine strategies that minimize lung de-recruitment during suctioning ${ }^{3-5,20}$; however, there are minimal data examining the effects of CSC cleaning on lung volumes and derecruitment. This study clearly shows that, when using a CSC without a valve in MHI, lung de-recruitment during CSC cleaning is a significant contributor to suctioninginduced lung de-recruitment. This repeated alveolar collapse and reopening has been shown to be harmful to the lung ${ }^{21,22}$ and should be avoided. This lung de-recruitment was entirely avoided when using a CSC with a valve; therefore, the use of this type of suction catheter should be advocated in clinical practice to avoid the negative effects of de-recruitment.

In contrast to the changes seen with CSC cleaning during MHI, EELV was seen to markedly increase with CSC cleaning in the absence of a valve during SIMV-VC. During CSC cleaning without a valve, the suction applied to clean the CSC was observed to continuously trigger the ventilator to deliver a breath due to flow trigger activation. The complex interaction between the suction, peak flow, and the inspiratory flow trigger leads to this constant ventilator cycling and interruption to delivered ventilation. Breath-stacking and the resultant increase in lung volume on a sustained and repeated basis could possibly contribute to alveolar damage and volutrauma, ${ }^{23}$ particularly in vulnerable patients with acute lung injury or ARDS. ${ }^{24}$ The lung volume changes that may result in these negative effects proved to be completely preventable by using a CSC with a valve.

The one previous study in this area ${ }^{25}$ examined the effects of CSC cleaning during volume-controlled ventilation in a bench experiment. This study tested a CSC with a valve against a CSC without a valve and measured the effect on ventilator circuit volume loss. It was found that the entire delivered volume was lost when cleaning the CSC without a valve. In contrast to this finding, the present study actually found an increase in the volume delivered. The difference in these 2 findings can be attributed to different ventilator trigger settings between the studies. Van Hooser et al ${ }^{25}$ set a pressure trigger of $-20 \mathrm{~cm} \mathrm{H}_{2} \mathrm{O}$ to avoid auto-triggering of the ventilator by the negative pressure generated by the suction. Therefore, with the ventilator not triggered to deliver a breath, no extra volume was delivered into the circuit, and volume was thus lost as a result of the suction applied during CSC cleaning.

However, we chose a more clinically relevant flow trigger of $-1.5 \mathrm{~L} / \mathrm{min}$ and, as such, observed the auto-triggering during SIMV-VC that the previously mentioned study tried to avoid. This resulted in the increase in EELV during CSC cleaning without a valve observed in the present study. It is then evident that, despite the ventilator trigger setting, CSC cleaning without a valve results in unintended and uncontrolled consequences to delivered ventilator breaths and the lung. In both studies, the presence of a valve between the patient's airway and the catheter cleaning chamber either minimized or completely negated the deleterious effects of suction on the functioning of the ventilator and on the lung.

The severity of adverse events associated with suctioning appear to be dependent on the duration of the suctioning procedure ${ }^{26}$; therefore, there are firm recommendations regarding limiting the period of airway suctioning to no more than $15 \mathrm{s.} .^{27}$ However, there are no time limits recommended for cleaning of CSCs largely because there has previously been no evidence regarding the effects of CSC cleaning on lung volume. If using a CSC without a valve, clinicians must be mindful of the effects of CSC cleaning on lung volume. Guidelines that limit the cleaning time should be put in place when using a CSC without a valve. Alternatively, CSCs with a valve should be routinely used particularly in patients who are vulnerable to the adverse effects associated with lung de-recruitment and barotrauma. At the time of this study, our ICU used a CSC without a valve in situ between the patient's airway and the sterility sleeve. The study findings have led us to change to the CSC with a valve, and this change has been cost-neutral to the ICU. On the basis of these findings, we 


\section{Lung Volume Changes During Cleaning of CSC}

believe that the use of CSCs without valves can no longer be justified due to the obvious lung de-recruitment and failure to maintain uninterrupted ventilation during the cleaning of the catheters.

This study has a number of limitations. A small sample of patients were studied; however, we were able to demonstrate statistically and clinically relevant differences between the 2 catheter types. Although postoperative cardiac surgical patients were recruited to ensure that a homogeneous group was studied, further investigation of other mechanically ventilated patient groups is required. Additionally, no long-term outcomes were assessed due to the randomized crossover design of the study. As only SIMV-VC and MHI were assessed in this study, further work needs to be done to investigate the effects of CSC cleaning in different ventilation modes.

\section{Conclusions}

In mechanically ventilated patients, using a CSC with a valve in place between the patient's airway and the catheter cleaning chamber prevents lung de-recruitment and ventilation interruption during cleaning of the catheter. The absence of such a valve results in significant lung volume loss during $\mathrm{MHI}$ and disruption to ventilation during SIMV-VC. Using a closed suctioning catheter with a valve should be considered the best practice for mechanically ventilated patients, particularly for patients with acute lung injury or ARDS.

\section{ACKNOWLEDGMENTS}

We thank Associate Professor Adrian Barnett (Institute of Biomedical Innovation, Queensland University of Technology, Brisbane, Australia) for his statistical support.

\section{REFERENCES}

1. Lachmann B. Open up the lung and keep the lung open. Intensive Care Med 1992;18(6):319-321.

2. Corley A, Spooner AJ, Barnett AG, Caruana LR, Hammond NE, Fraser JF. End-expiratory lung volume recovers more slowly after closed endotracheal suctioning than after open suctioning: a randomized crossover study. J Crit Care 2012;27(6):742.e1-742.e7.

3. Fernández MD, Piacentini E, Blanch L, Fernández R. Changes in lung volume with three systems of endotracheal suctioning with and without pre-oxygenation in patients with mild-to-moderate lung failure. Intensive Care Med 2004;30(12):2210-2215.

4. Maggiore SM, Lellouche F, Pigeot J, Taille S, Deye N, Durrmeyer $\mathrm{X}$, et al. Prevention of endotracheal suctioning-induced alveolar derecruitment in acute lung injury. Am J Respir Crit Care Med 2003; 167(9):1215-1224.

5. Cereda M, Villa F, Colombo E, Greco G, Nacoti M, Pesenti A. Closed system endotracheal suctioning maintains lung volume during volume-controlled mechanical ventilation. Intensive Care Med 2001;27(4):648-654.

6. Grant CA, Fraser JF, Dunster KR, Schibler A. The assessment of regional lung mechanics with electrical impedance tomography: a pilot study during recruitment manoeuvres. Intensive Care Med 2009; 35(1):166-170.

7. Lindgren S, Odenstedt H, Olegård C, Söndergaard S, Lundin S, Stenqvist O. Regional lung derecruitment after endotracheal suction during volume- or pressure-controlled ventilation: a study using electric impedance tomography. Intensive Care Med 2007;33(1):172180.

8. Tingay DG, Copnell B, Grant CA, Dargaville PA, Dunster KR, Schibler A. The effect of endotracheal suction on regional tidal ventilation and end-expiratory lung volume. Intensive Care Med 2010;36(5):888-896.

9. Brown BH, Barber DC, Seagar AD. Applied potential tomography: possible clinical applications. Clin Phys Physiol Meas 1985;6(2): 109-121.

10. Caruana LR, Paratz J, Chang AT, Fraser JF. Electrical impedance tomography in the clinical assessment of lung volumes following recruitment manoeuvres. Phys Ther Rev 2011;16(1):66-74.

11. Bodenstein M, David M, Markstaller K. Principles of electrical impedance tomography and its clinical application. Crit Care Med 2009; 37(2):713-724.

12. Costa ELV, Lima RG, Amato MBP. Electrical impedance tomography. Curr Opin Crit Care 2009;15(1):18-24.

13. Putenson C, Wrigge H, Zinserling J. Electrical impedance tomography guided ventilation. Curr Opin Crit Care 2007;13(3):344-350.

14. Hinz J, Hahn G, Neumann P, Sydow M, Mohrenweiser P, Hellige G, Burchardi H. End-expiratory lung impedance change enables bedside monitoring of end-expiratory lung volume change. Intensive Care Med 2003;29(1):37-43.

15. van Genderingen HR, van Vught AJ, Jansen JR. Estimation of regional lung volume changes by electrical impedance pressures tomography during a pressure-volume maneuver. Intensive Care Med 2003;29(2):233-240.

16. Freytag CC, Thies FL, König W, Welte T. Prolonged application of closed in-line suction catheters increases microbial colonization of the lower respiratory tract and bacterial growth on catheter surface. Infection 2003;31(1):31-37.

17. Hagler DA, Traver GA. Endotracheal saline and suction catheters: sources of lower airway contamination. Am J Crit Care 1994;3(6): 444-447.

18. Inglis TJ, Lim TM, Ng ML, Tang EK, Hui KP. Structural features of tracheal tube biofilm formed during prolonged mechanical ventilation. Chest 1995;108(4):1049-1052.

19. Sottile FD, Marrie TJ, Prough DS, Hobgood CD, Gower DJ, Webb LX, Costerton JW, et al. Nosocomial pulmonary infection: possible etiologic significance of bacterial adhesion to endotracheal tubes. Crit Care Med 1986;14(4):265-270.

20. Dyhr T, Bonde J, Larsson A. Lung recruitment manoeuvres are effective in regaining lung volume and oxygenation after open endotracheal suctioning in acute respiratory distress syndrome. Crit Care 2003;7(1):55-62.

21. Amato MB, Barbas CS, Medeiros DM, Magaldi RB, Schettino GP, Lorenzi-Filho G, et al. Effect of a protective-ventilation strategy on mortality in the acute respiratory distress syndrome. N Engl J Med 1998;338(6):347-354.

22. Muscedere JG, Mullen JB, Gan K, Slutsky AS. Tidal ventilation at low airway pressures can augment lung injury. Am J Respir Crit Care Med 1994;149(5):1327-1334.

23. The Acute Respiratory Distress Syndrome Network. Ventilation with lower tidal volumes as compared with traditional tidal volumes for acute lung injury and the acute respiratory distress syndrome. N Engl J Med 2000;342(18):1301-1308.

24. Bernard GR, Artigas A, Brigham KL, Carlet J, Falke K, Hudson L, et al. Report of the American-European consensus conference on ARDS: definitions, mechanisms, relevant outcomes and clinical trial 


\section{Lung Volume Changes During Cleaning of CSC}

coordination. The Consensus Committee. Intensive Care Med 1994; 9(1):225-232.

25. Van Hooser T, Madsen E, Flood T. New closed suction catheter design reduces ventilator volume loss during simulated suction events. 48th AARC Congress, October 5-8, 2002, Tampa Bay, Florida
26. Pedersen CM, Rosendahl-Nielsen M, Hjermind J, Egerod I. Endotracheal suctioning of the adult intubated patient-what is the evidence? Intensive Crit Care Nurs 2009;25(1):21-30.

27. Restrepo RD. AARC Clinical Practice Guidelines: from "referencebased" to "evidence-based". Respir Care 2010;55(6):787-789.

This article is approved for Continuing Respiratory Care Education credit. For information and to obtain your CRCE

(free to AARC members) visit

www.rcjournal.com 